\title{
Cyclicities and clusters in the lacustrine sequence of Heqing basin (SW China): Its use for dating and palaeoenvironmental reconstruction
}

\author{
Srinivasa R Goddu†*, Shouyun Hu‡ and Erwin Appel† \\ † Institut for Geosciences, University of Tuebingen, Sigwartstrasse 10, 72076 Tuebingen, GERMANY \\ $\neq$ Nanjing Institute of Geography and Limnology, Chinese Academy of Sciences, 73 East Beijing Rd, Nanjing 210008, CHINA \\ * To whom correspondence should be addressed.E-mail: srinivasa.rao@uni-tuebingen.de
}

Heqing basin is situated in Yunnan province (SW China), at the southeastern margin of the Himalayan-Tibetan Plateau area. This region is suitable to study the evolution of the southwest monsoon and to identify regional tectonic events. A $168 \mathrm{~m}$ drillcore comprising a continuous succession of fine-grained almost uniform lacustrine sediments was recovered from the center of the basin. A High-resolution data set of palaeoenvironmental proxies is available from this core (Yang et al. 2000, Hu et al. subm.). The present study uses time series analysis and multivariate statistics to interpret these data and also uses spectral analysis in combination with magnetostratigraphy and radiometric dating to provide an optimum age frame.

Time series analysis on carbonate content and magnetic concentration parameters $(\chi$ : susceptibility, SIRM: saturation isothermal magnetization, ARM: anhysteretic remanent magnetization) show a remarkable cyclicity with a predominating spectral peak at about 15-20 m (wavelength domain). There are two clear age markers, i.e. a ${ }^{14} \mathrm{C}$-age of 51.6 $\mathrm{ka}$ at a depth of $7.3 \mathrm{~m}$ and the Brunhes-Matuyama boundary at a depth of $141.5 \mathrm{~m}$. They indicate that the dominating wavelength represents an eccentricity cycle. Spectral analysis with sliding windows (different window lengths of 40-80 m) reveal a variation of this main spectral peak changing from 18.5 $\mathrm{m}$ in the lower part (> $65 \mathrm{~m}$ depth) to $14.5 \mathrm{~m}$ in the upper part ( $<65 \mathrm{~m}$ depth). Using tie points from ${ }^{14} \mathrm{C}$ dating $(7.3 \mathrm{~m})$, Blake event (16.3-17.5 m), discrete change of sedimentation rate at 65 $\mathrm{m}$ (calculated from spectral data of sliding windows), BrunhesMatuyama boundary ( $141.5 \mathrm{~m})$ and magnetic polarity transition related to top of Jaramillo $(167.0 \mathrm{~m})$, a tuned age model is obtained by cubic spline interpolation. This tuned age model dates the cores from 1,001 to $5 \mathrm{ka}$. It results in a significant Milankovitch spectrum for whole-core carbonate data showing the 95-kyr eccentricity, obliquity (41 kyr) and precession (23 and $19 \mathrm{kyr})$. Spectral results of magnetic concentration parameters also show eccentricity and obliquity, but not precession. Alternative depth-to-age transfer functions were tested, i.e., a linear model (tie point ${ }^{14} \mathrm{C}$ age), a cyclostratigraphic model (using bandpass-filtered carbonate data corresponding to $95-\mathrm{kyr}$ eccentricity cycles) and correlation of carbonate variation to the marine oxygen isotope curve. However, none of these approaches result in a Milankovitch spectrum of whole-core carbonate data comparably significant as for the tuned age model.

According to the spectral results the core clearly shows a control of global palaeoclimatic variations. To identify a trend through time the spectral power was further analyzed by wavelet transform of carbonate and susceptibility $(\chi)$. From the wavelet power spectra it is evident that eccentricity was mostly predominant within the period of 750-300 ka, whereas obliquity and precession were strongest between 700-500 ka. Correlation coefficients $(\mathrm{R})$ of carbonate and $\chi$ were determined for depth intervals of different lengths ( $2.5 \mathrm{~m}$ to $15 \mathrm{~m}$ ). Negative correlation dominates within depths of 50-150 m, whereas positive correlation is observed below $150 \mathrm{~m}$ and also dominates above $50 \mathrm{~m}$. Surprisingly, R-values of small depth intervals (2.5 and 3.5 $\mathrm{m})$ show a cyclic behaviour with clear obliquity and precssion peaks. This striking result might be explained by a mixed and varying global and regional control of carbonate and $\chi$. It seems that variation of magnetic concentration is dependent on both, magnetic mineral content and dilution by carbonate, with different contribution at different times. The change of sedimentation rate at about $65 \mathrm{~m}$ (and probably also in the lower part of the core) clearly points to a regional effect. Mineral magnetic indicators, i.e. ARM/SIRM-ratio and S-ratio, and pollen data (showing no cyclic behaviour) also are evidence of a regional influence.

The regional palaeoenvironmental changes can be better reconstructed by multivariate statistics applying fuzzy c-means cluster analysis. The most significant result could be obtained with a 3-cluster solution including magnetic data (ARM/SIRM, $\chi$ ) carbonate content, and pollen concentration (tsuga and total tree). The parameter selection is based on analysis of Euclidean linkage distances (dendrogram analysis) and can be also well explained by their meaning. Carbonate and $\chi$ represent a global effect, however with different regional influence (shown by Rvalues). ARM/SIRM is an indicator for grain size variations which are probably caused by alteration of magnetite to maghemite (weathering during warmer and more humid conditions).Values of $\chi$ are also dependent on this magneto-mineralogical alteration. Tsuga documents temperate-humid phases and total tree is indicative for extreme cold-dry conditions (maghemitization leading to lower magnetic concentration). The resulting cluster probabilities confirm the subdivision of the core into three parts, i.e. below about $120 \mathrm{~m}$ (ca $700 \mathrm{ka}$ ), 120-65 m and above $65 \mathrm{~m}$ (ca $420 \mathrm{ka}$ ). Further subdivision and interpretations in terms of palaeoclimate are presented by Appel et al. (this volume).

\section{References}

Yang X, S Wang, G Tong and X Jiang. 2000. Vegetational and climatic responses to tectonic uplift in the Heqing Basin of Yunnan Province during the past 1.0 Ma. Acta Micropaleontologica Sinica 17(2): 207217

Hu S, SR Goddu, E Appel, K Verosub, X Yang and S Wang. Submitted. Palaeoclimatic changes over the past one million years derived from lacustrine sediments of Heqing basin (Yunnan, China). Quarternary Int. 